\title{
Right heart function and prediction of respiratory morbidity in patients undergoing pneumonectomy with moderately severe cardiopulmonary dysfunction
}

Detailed hemodynamic monitoring was performed in 20 patients undergoing pneumonectomy with moderately severe chronic obstructive pulmonary disease. Flow-directed pulmonary artery catheters capable of determining thermal dilution right ventricular ejection fraction and other indexes of right ventricular performance were placed in each patient. The mean actual and percent values for forced expiratory volume in 1 second in this group were $1.8 \pm 0.5 \mathrm{~L}$ and $66 \% \pm 18 \%$, respectively. Pulmonary hypertension was present in $76.5 \%$ of patients at the baseline nonintubated state. At pulmonary artery clamping, $53.8 \%$ of this subgroup had no change or a mean drop of $8 \mathrm{~mm} \mathbf{~ H g}$ in pressure. The remaining had a mean rise of $12 \mathrm{~mm} \mathrm{Hg}$. Mean systolic pulmonary artery pressures in this subset $(41 \mathrm{~mm} \mathrm{Hg})$ did not change from the nonintubated state to pulmonary artery clamping. Patients with normal pulmonary artery pressures before intubation had an average rise of only $4 \mathrm{~mm}$ $\mathrm{Hg}$ at pulmonary artery clamping. In the immediate postoperative period, only $10.0 \%$ of the entire group had normal pulmonary artery pressures. Right ventricular ejection fraction and pulmonary vascular resistance were normal in $58.8 \%$ and $94.1 \%$, respectively, at the baseline nonintubated state. Abnormal right ventricular ejection fraction values $(<\mathbf{4 5} \%)$ were present in $\mathbf{7 0 . 0} \%$ of patients at pulmonary artery clamping; $\mathbf{2 5 . 0} \%$ fell below $35 \%$. Pulmonary vascular resistance increased above 200 dyne $\cdot \mathrm{sec} \cdot \mathrm{cm}^{-5}$ in $\mathbf{3 0 . 0} \%$ at pulmonary artery clamping. No correlation was found between right ventricular ejection fraction and pulmonary vascular resistance or pulmonary artery pressure during operation. No pulmonary function test or hemodynamic variable measured in this study accurately predicted the days of hospital stay or early postoperative cardiopulmonary morbidity. At the baseline nonintubated state, no parameter consistently predicted late New York Heart Association class III/IV. At the time of pulmonary artery clamping, a right ventricular ejection fraction of less than $35 \%$, a pulmonary vascular resistance greater than or equal to 200 dyne $\cdot \mathrm{sec} \cdot \mathrm{cm}^{-5}$, and a pulmonary vascular resistance/right ventricular ejection fraction ratio greater than or equal to 5.0 predicted the development of long-term cardiopulmonary disability. Thirteen patients $(65.0 \%)$ in this series with abnormally low preoperative pulmonary function could have been excluded from pneumonectomy. Only five of 13 patients $(38.5 \%)$ had late class III/IV symptoms. Four of these five patients had a right ventricular ejection fraction less than $35 \%$ during operation. Those patients with a right ventricular ejection fraction greater than or equal to $35 \%$ and normal pulmonary vascular resistance appear to have sufficient pulmonary vascular capacitance to tolerate pneumonectomy despite the presence of pulmonary hypertension and abnormally low pulmonary function tests. ( $J$ THORAC CARDIOVASC SURG 1994;108:169-75)

Joseph W. Lewis, Jr., MD, Mostafa Bastanfar, MD, Fathy Gabriel, MD, and

Edward Mascha, MS, Detroit, Mich.

From the Division of Thoracic and Cardiac Surgery, Division of Anesthesiology, and Division of Biostatistics and Research Epidemiology, Henry Ford Hospital, Detroit, Mich.

Received for publication June 9, 1993.

Accepted for publication Dec. 14, 1993.
Address for reprints: Joseph W. Lewis, Jr., MD, Division of Thoracic and Cardiac Surgery, Henry Ford Hospital, 2799 W. Grand Blvd., Detroit, MI 48202

Copyright ${ }^{(} 1994$ by Mosby-Year Book, Inc.

$0022-5223 / 94 \$ 3.00+0 \quad 12 / 1 / 54080$ 
Right ventricular performance has been well documented in patients with varying degrees of chronic obstructive pulmonary disease (COPD) ${ }^{1-5}$ However, surprisingly little information exists concerning activity of the right heart during pneumonectomy in patients with moderately severe COPD ${ }^{6,7}$ Controversy also exists about the ability to predict respiratory complications by a variety of preoperative tests. ${ }^{8-13}$ This study was undertaken to examine right heart performance during and immediately after pneumonectomy. Hemodynamic and derived indexes of right ventricular (RV) activity combined with preoperative pulmonary function testing were sought to predict early and late cardiopulmonary dysfunction in these patients.

\section{Patients and methods}

After obtaining informed consent, standard hemodynamic monitoring was performed in 20 patients with moderately severe cardiopulmonary dysfunction requiring pneumonectomy. Baseline pulmonary function tests with arterial blood gases, split perfusion lung scans, and maximal oxygen consumption determinations were obtained before the operation in patients with planned pneumonectomy. Only spirometry was available in three patients where pneumonectomy was an unexpected procedure. A radial artery cannula and flow-directed pulmonary artery (PA) catheter capable of measuring RV ejection fraction (RVEF; Baxter Healthcare Corp., Irvine, Calif.) were placed in each patient before induction of anesthesia, with the exception of the three patients described previously. In these three, the PA catheter was placed after the completion of a lung cancer staging procedure. Indications for placement of this catheter included a percentage of forced expiratory volume at one second $\left(F E V_{1}\right)$ or maximum voluntary ventilation less than $60 \%$ of predicted value, an $\mathrm{FEV}_{1}$ less than $2.0 \mathrm{~L}$, a split perfusion lung scan remaining $\mathrm{FEV}_{1}$ less than $800 \mathrm{ml}$, or a maximal oxygen consumption of less than $15 \mathrm{ml} / \mathrm{kg}$ per minute. If the PA catheter was palpated in the ipsilateral PA, this vessel was finger occluded while the device was withdrawn slightly and advanced into the contralateral PA. Hemodynamic measurements were made at the baseline nonintubated state after intubation, in the thoracotomy position with one-lung ventilation at PA clamping, and the supine position immediately before leaving the operating room. Three injections of $10 \mathrm{ml}$ of iced $5 \%$ dextrose in water were made at each stage unless results deviated greater than $10 \%$. Signals from the PA catheter were processed through an REF-1 ejection fraction cardiac output computer (Baxter Healthcare Corp., Santa Ana, Calif.). At least 10 minutes were allowed for stabilization before measurements were made at each stage. In selected patients, the RVEF catheter was left in place for 24 hours. The following measurements/derivatives were obtained at each station: right atrial and pulmonary capillary wedge pressure, PA and systemic pressures, cardiac index, stroke volume index, RVEF, RV end-systolic volume index, RV end-diastolic volume index, peak RV systolic pressure/RV end-systolic volume index, systemic vascular resistance, pulmonary vascular resistance (PVR), and PVR/RVEF. No inotropic or short-acting vasodilating drugs were used during operation in any patient.

Patients were considered to have pulmonary hypertension if the systolic and mean PA pressures were greater than 30 and 20 mm $\mathrm{Hg}$, respectively. 14

Statistical analysis. To explore possible relationships among the previously mentioned variables, we calculated Pearson correlations at the baseline nonintubated, intubated, and PA clamp stages for all combinations of the hemodynamic measurements outlined previously. Because multiple comparisons were made during three stages of operation, the overall alpha level of 0.05 was maintained with the use of a significance criterion of 0.017 $(0.05 / 3)$ for each stage through a Bonferroni correction. Because large numbers of correlations were tested within each stage ( $n=55$ ), a further adjustment of the significance criterion was made; significance was considered at $p<0.01$. The significance criterion of 0.01 was also used for the analyses described later, with alpha equaling 0.05 for each hypothesis. Mean changes in hemodynamic variables during operation were tested with paired $t$ tests (excluding the three patients without baseline nonintubated values). Differences in mean RV performance variables among patients with normal and elevated PA pressure and those with RVEF less than $35 \%$ and those with RVEF greater than or equal to $35 \%$ were compared with Student's $t$ test for nonintubation and PA clamped stages. The proportion with late New York Heart Association (NYHA) class I/II versus III/IV was compared for patients above and below specific cutoff points for hemodynamic variables with Fisher's exact test because of the small sample size.

Linear regression analyses were used to find potential predictors of length of hospital stay from any of the baseline pulmonary function tests or measured hemodynamic variables. Pulmonary function and hemodynamic values before and after intubation and PA clamped stages were tested as possible predictors of immediate postoperative cardiorespiratory complications with Student's $t$ tests. NYHA classification groups I/II and III/IV were compared on the mean of the same pulmonary function and hemodynamic variables from each of the baseline, intubation, and PA clamped stages with two-sided Student's $t$ tests.

In the following results, the null hypothesis was rejected with $95 \%$ confidence where a test was significant. However, because of the statistically small sample size in this study, caution must be used in the interpretation of the lack of statistical significance when the null hypothesis was not rejected.

\section{Results}

The mean age of this 20-patient cohort was $61.7 \pm$ 11.5 years (range 25 to 81 years) with a male/female ratio of 1.5:1. Completion pneumonectomy was performed in 3 of 20 patients (15.0\%). Operation was performed for lung cancer in 19 patients and complications of tuberculosis in 1 patient. Pulmonary function data are presented in Table I. The $\mathrm{FEV}_{1}$ was less than 2.0 $\mathrm{L}$ in 13 of 20 patients $(65.0 \%)$ and less than or equal to $1.5 \mathrm{~L}$ in 7 of 20 patients (35.0\%). Documented coronary artery or valvular heart disease was present in 3 of 20 patients $(15.0 \%)$. Mean hemodynamic values during operation are seen in Table II. In 5 patients where the PA catheter was left in place at least 12 hours after the operation, no hemodynamic parameter measured after 
the operation showed a statistically significant change from that at the baseline nonintubated state.

The response of PA pressure at PA clamping was variable (Fig. 1). Patients with normal PA pressures before intubation had a mean change of $4 \mathrm{~mm} \mathrm{Hg}$ at PA clamping. In 13 patients $(76.5 \%)$ with pulmonary hypertension, PA pressures at PA occlusion showed no change or a mean drop of $8 \mathrm{~mm} \mathrm{Hg}$ in seven patients $(53.8 \%)$. The remaining patients in this subgroup had a mean rise of 12 $\mathrm{mm} \mathrm{Hg}$ at PA clamping. Mean PA pressures paralleled their systolic counterparts. No desaturation or arrhythmia was seen in any patient at this point. Elevated PA pressures were present in 18 of 20 patients $(90.0 \%)$ in the immediate postoperative period. No statistically signifcant differences were found in mean RVEF or PVR values in patients with normal versus those with elevated PA pressures at the baseline nonintubated state or during PA clamping (Table III).

Mean RVEF values gradually declined from a high of $45 \% \pm 10 \%$ before intubation to $39 \% \pm 8 \%$ at the time of PA clamping (paired $t$ test, $p=0.082$; not significant). At the baseline nonintubated state, RVEF was normal $(\geq 45 \%)^{1}$ in 10 of 17 patients $(58.8 \%)$ and less than $35 \%$ in only 3 of 17 patients (17.6\%). At PA clamping, RVEF was normal in only 6 of $20(30.0 \%)$ and less than $35 \%$ in 5 of 20 patients $(25.0 \%)$. Patients with normal RVEF before intubation generally showed a significant decline in this value at PA clamping, whereas most with subnormal levels showed no change (Fig. 2). Table IV illustrates the differences in measured hemodynamic parameters at various levels of RVEF. No significant correlations between RVEF and PVR or PA pressures at any measurement point.

Pulmonary vascular resistance was greater than or equal to 200 dyne $\cdot \mathrm{sec} \cdot \mathrm{cm}^{-5}$ in 1 of 17 patients $(5.9 \%)$ at the baseline nonintubated state and 6 of $20(30.0 \%)$ after intubation. At one-lung ventilation, PVR decreased below 200 dyne $\cdot \mathrm{sec} \cdot \mathrm{cm}^{-5}$, with the exception of a single patient with the elevated value at baseline. At PA clamping, PVR again rose to $200 \mathrm{dyne} \cdot \mathrm{sec} \cdot \mathrm{cm}^{-5}$ or more in patients with elevated values at intubation. Although RVEF decreased in this six-patient subset from a mean of $44 \% \pm 12 \%$ at the beginning of operation to $36 \% \pm 10 \%$ at PA clamping, this change was not statistically significant (paired $t$ test, $p=0.1259$ ). Pearson correlation analysis showed a significant direct relationship between PVR and systolic PA pressure before intubation (correlation coefficient $=0.733, p<0.01$ ) but this relationship did not persist through operation. With the exception of two patients, RV volumes were elevated throughout operation. RV end-systolic volume index ranged between 55 and $61 \mathrm{ml} / \mathrm{m}^{2}$ (normal $<33 \mathrm{ml} / \mathrm{m}^{2}$ ),
Table I. Preoperative pulmonary function data

\begin{tabular}{lc}
\hline & Mean \pm standard deviation \\
\hline $\mathrm{FVC}(\%)$ & $81 \pm 18$ \\
$\mathrm{FEV}_{1}(\%)$ & $66 \pm 18$ \\
$\mathrm{FEV}_{1}(\mathrm{~L})$ & $1.8 \pm 0.5$ \\
$\mathrm{FEV}_{1} / \mathrm{FVC} \mathrm{( \% )}$ & $64 \pm 14$ \\
$\mathrm{MVV}(\%)$ & $67 \pm 16$ \\
Nuclear lung remaining FEV & \\
$\quad \%$ Predicted & $39 \pm 10$ \\
$\mathrm{Milliliters}$ & $1065 \pm 339$ \\
$\mathrm{~V} \mathrm{Max} \mathrm{O}_{2}(\mathrm{ml} / \mathrm{kg} / \mathrm{min})$ & $12.6 \pm 0.8$ \\
$\mathrm{PaO}_{2}(\mathrm{~mm} \mathrm{Hg})$ & $78 \pm 12$ \\
$\mathrm{PaCO}_{2}(\mathrm{~mm} \mathrm{Hg})$ & $37 \pm 7$ \\
\hline
\end{tabular}

$F V C$, Forced vital capacity; $F E V_{l}$, forced expiratory volume at 1 second; $M V V$, maximal voluntary ventilation; $V M a x \mathrm{O}_{2}$, maximum exercise oxygen consumption; $\mathrm{PaO}_{2}$, systemic arterial oxygen tension (fraction inspired oxygen, 0.21 ); $\mathrm{PaCO}_{2}$, systemic carbon dioxide tension.

whereas $\mathrm{RV}$ end-diastolic volume index fell between 90 to $101 \mathrm{ml} / \mathrm{m}^{2}$ (normal $<79 \mathrm{ml} / \mathrm{m}^{2}$ ). ${ }^{2} \mathrm{RV}$ end-systolic volume index showed a strong inverse relationship to RVEF through all measuring stages. The peak RV pressure/RV end-systolic volume index ratio, a reflector of $\mathrm{RV}$ contractility, ${ }^{2}$ remained constant throughout operation (Table II). Significant decrements in RVEF, cardiac index, and stroke volume index occurred from the baseline nonintubated state to PA clamping.

Linear regression analysis showed no relationship between any pulmonary function test or derived hemodynamic variable and length of hospital stay or the development of in-hospital cardiorespiratory morbidity at the 0.05 significance level. Immediate postoperative respiratory complications developed in 4 of 20 patients (20.0\%). One death caused by adult respiratory distress syndrome occurred in a 53-year-old patient with an $\mathrm{FEV}_{1}$ of $2.0 \mathrm{~L}$ (73\% of normal), a split nuclear lung scan remaining $\mathrm{FEV}_{1}$ of $1378 \mathrm{ml}$, an RVEF between $39 \%$ and $50 \%$, and PVR less than 150 dyne $\cdot \mathrm{sec} \cdot \mathrm{cm}^{-5}$ during operation.

At a mean follow-up of $9.7 \pm 6.3$ months, 13 of 19 patients (68.4\%) were in NYHA classification I/II. Late cardiopulmonary dysfunction developed in 3 of 19 patients $(15.8 \%)$ who had a baseline nonintubated RVEF less than $35 \%$, a PVR greater than or equal to 200 dyne $\cdot \mathrm{sec} \cdot \mathrm{cm}^{-5}$, or PVR/RVEF ratio greater than or equal to 5.0. At the time of PA clamping, the mean RVEF for those patients in late NYHA class I/II was $43 \% \pm 6 \%$ compared with $31 \% \pm 8 \%$ for those in NYHA class III/IV (two-sided Student's $t$ test $p=0.002$ ). Fisher's exact test showed that an RVEF cutpoint of 35\% at PA clamping accurately predicted late NYHA class $(p=0.006)$. In five patients with an RVEF less than $35 \%$, four of five patients $(80.0 \%)$ were in late NYHA class III/IV. In the cases in which one element 
Table II. Mean measured hemodynamic parameters during pneumonectomy

\begin{tabular}{|c|c|c|c|c|c|}
\hline & $\begin{array}{c}\text { Baseline } \\
\text { nonintubated }\end{array}$ & Intubated & $\begin{array}{c}\text { One-lung } \\
\text { ventilation }\end{array}$ & PA clamped & $\begin{array}{c}\text { End of } \\
\text { operation }\end{array}$ \\
\hline $\operatorname{RAP}(\mathrm{mm} \mathrm{Hg})$ & $11 \pm 5$ & $13 \pm 5$ & $14 \pm 5$ & $14 \pm 5$ & $12 \pm 6$ \\
\hline Systolic PAP (mm Hg) & $37 \pm 9$ & $35 \pm 8$ & $39 \pm 11$ & $39 \pm 9$ & $43 \pm 11$ \\
\hline Mean PAP $(\mathrm{mm} \mathrm{Hg})$ & $26 \pm 6$ & $25 \pm 6$ & $29 \pm 8^{*}$ & $28 \pm 7$ & $30 \pm 9$ \\
\hline PCWP (mm Hg) & $15 \pm 4$ & $16 \pm 4$ & $20 \pm 8$ & $18 \pm 6$ & $17 \pm 7$ \\
\hline $\mathrm{CI}\left(\mathrm{L} / \mathrm{min} / \mathrm{m}^{2}\right)$ & $3.5 \pm 1.2$ & $2.8 \pm 0.8$ & $3.2 \pm 0.8$ & $2.9 \pm 0.7 \dagger$ & $2.9 \pm 0.8$ \\
\hline $\operatorname{SVI}\left(\mathrm{ml} / \mathrm{m}^{2}\right)$ & $42 \pm 11$ & $35 \pm 9$ & $40 \pm 9$ & $35 \pm 8^{* \dagger}$ & $36 \pm 10$ \\
\hline RVEF (\%) & $45 \pm 10$ & $40 \pm 9$ & $42 \pm 10$ & $39 \pm 8 \dagger$ & $38 \pm 11$ \\
\hline $\operatorname{RVESVI}\left(\mathrm{ml} / \mathrm{m}^{2}\right)$ & $55 \pm 20$ & $55 \pm 20$ & $59 \pm 21$ & $57 \pm 16$ & $61 \pm 23$ \\
\hline RVEDVI $\left(\mathrm{ml} / \mathrm{m}^{2}\right)$ & $97 \pm 22$ & $90 \pm 22$ & $101 \pm 22$ & $92 \pm 17$ & $97 \pm 25$ \\
\hline PVR (dyne $\cdot \mathrm{sec} \cdot \mathrm{cm}^{-5}$ ) & $130 \pm 67$ & $153 \pm 69$ & $124 \pm 41$ & $157 \pm 79$ & $192 \pm 81$ \\
\hline PVR/RVEF & $3.2 \pm 2.3$ & $4.0 \pm 2.2$ & $3.2 \pm 1.4$ & $4.4 \pm 3.1 \dagger$ & $5.8 \pm 4.6$ \\
\hline $\mathrm{RVP} / \mathrm{V}\left(\mathrm{mm} \mathrm{Hg} / \mathrm{ml} / \mathrm{m}^{2}\right)$ & $0.7 \pm 0.3$ & $0.6 \pm 0.2$ & $0.7 \pm 0.4$ & $0.7 \pm 0.3$ & $0.8 \pm 0.3$ \\
\hline
\end{tabular}

$R A P$, Right atrial pressure; $P A P$, PA pressure; $P C W P$, pulmonary capillary wedge pressure; $C I$, cardiac index; $S V I$, stroke volume index: $R V E S V I$, RV endsystolic volume index; $R V E D V I, \mathrm{RV}$ end-diastolic volume index; $P V R$, pulmonary vascular resistance; $R V P / V$, peak $\mathrm{RV}$ pressure/RV end-systolic volume index ratio.

* Statistically significant change from preceding value (paired $t$ test $p<0.01$ )

$\Varangle$ Statistically significant changes from the baseline nonintubated state to PA clamping (paired $t$ test $p<0.01$ )

Table III. Differences in mean $R V$ performance parameters with normal and elevated $P A$ pressures

\begin{tabular}{|c|c|c|c|c|}
\hline & \multicolumn{2}{|c|}{ Baseline nonintubated } & \multicolumn{2}{|c|}{ PA clamped } \\
\hline & $\begin{array}{c}\text { Normal } \\
\text { systolic PAP } \\
(\mathrm{n}=4)\end{array}$ & $\begin{array}{c}\text { Pulmonary } \\
\text { hypertension } \\
(\mathrm{n}=13) \\
\end{array}$ & $\begin{array}{c}\text { Normal } \\
\text { systolic } P A P \\
(\mathrm{n}=3)\end{array}$ & $\begin{array}{c}\text { Pulmonary } \\
\text { hypertension } \\
(\mathrm{n}=17)\end{array}$ \\
\hline Systolic PAP (mm Hg) & $26 \pm 4$ & $41 \pm 7^{*}$ & $25 \pm 4$ & $41 \pm 7^{*}$ \\
\hline Mean PAP $(\mathrm{mm} \mathrm{Hg})$ & $18 \pm 4$ & $28 \pm 5^{*}$ & $16 \pm 6$ & $30 \pm 6^{*}$ \\
\hline $\mathrm{RAP}(\mathrm{mm} \mathrm{Hg})$ & $9 \pm 6$ & $12 \pm 5$ & $6 \pm 4$ & $15 \pm 4^{*}$ \\
\hline PCWP $(\mathrm{mm} \mathrm{Hg})$ & $13 \pm 4$ & $16 \pm 4$ & $11 \pm 5$ & $19 \pm 5$ \\
\hline $\mathrm{CI}\left(\mathrm{L} / \mathrm{min} / \mathrm{m}^{2}\right)$ & $2.8 \pm 0.5$ & $3.8 \pm 1.2$ & $3.0 \pm 0.4$ & $2.8 \pm 0.7$ \\
\hline $\operatorname{SVI}\left(\mathrm{ml} / \mathrm{m}^{2}\right)$ & $34 \pm 7$ & $44 \pm 11$ & $37 \pm 7$ & $34 \pm 9$ \\
\hline RVEF $(\%)$ & $38 \pm 12$ & $47 \pm 9$ & $41 \pm 7$ & $39 \pm 9$ \\
\hline $\operatorname{RVESVI}\left(\mathrm{ml} / \mathrm{m}^{2}\right)$ & $64 \pm 36$ & $52 \pm 14$ & $52 \pm 6$ & $58 \pm 18$ \\
\hline RVEDVI $\left(\mathrm{ml} / \mathrm{m}^{2}\right)$ & $98 \pm 39$ & $97 \pm 17$ & $90 \pm 4$ & $93 \pm 18$ \\
\hline PVR (dyne $\cdot \mathrm{sec} \cdot \mathrm{cm}^{-5}$ ) & $87 \pm 10$ & $144 \pm 72$ & $86 \pm 23$ & $161 \pm 89$ \\
\hline PVR/RVEF & $2.6 \pm 0.9$ & $3.4 \pm 2.6$ & $2.2 \pm 0.9$ & $4.8 \pm 3.2$ \\
\hline $\mathrm{RVP} / \mathrm{V}\left(\mathrm{mm} \mathrm{Hg} / \mathrm{ml} / \mathrm{m}^{2}\right)$ & $0.6 \pm 0.3$ & $0.8 \pm 0.3$ & $0.5 \pm 0.0$ & $0.7 \pm 0.3$ \\
\hline
\end{tabular}

For abbreviations, see Table II.

*Statistically significant difference from value in corresponding column (Student's t test, $p<0.01$ )

of RVEF-PVR measurements was abnormal, six of the eight patients $(75.0 \%)$ were in late class III/IV. In the cases in which both values were normal, however, no patient was in class III/IV. A PVR/RVEF ratio of greater than or equal to 5.0 predicted late NYHA class III/IV in five of six patients $(83.3 \%)$. Recommended preoperative pulmonary function testing could have excluded 13 of 20 patients $(65.0 \%)$ in this study from pneumonectomy. ${ }^{15,16}$ Five of the 13 patients $(38.5 \%)$ of this subgroup had late class III/IV symptoms. Two had an RVEF less than 35\%, a normal PVR, and a PVR/ $R$ VEF ratio greater than or equal to 5.0 at baseline. Two additional patients had elevated PVR/RVEF ratios during operation. In the remaining seven who stayed in late class I/II, only one had an RVEF less than $35 \%$ before intubation.

\section{Discussion}

During progression of COPD, a critical reduction in cross-sectional area of the pulmonary vascular bed can cause elevation of PA pressures and worsening of RV performance, resulting in cor pulmonale. Despite the presence of pulmonary hypertension in most patients in this series, PA pressures changed little at the time of PA clamping. Although some reduction in the pulmonary vascular bed occurred as a result of COPD, sufficient pulmonary vascular capacitance volume was present to prevent severe elevation of PA pressures with pneumonec- 

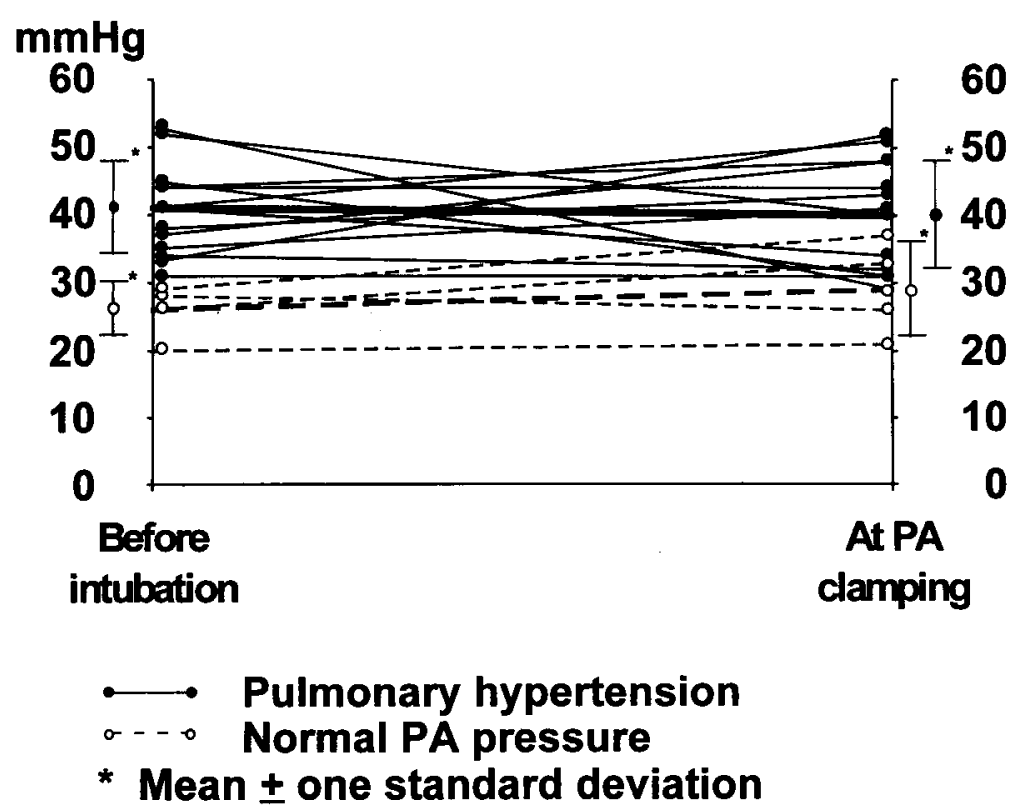

Fig. 1. Changes in systolic PA pressure from the baseline, nonintubated state to PA clamping during pneumonectomy. Mean changes in the two groups were not statistically significant.
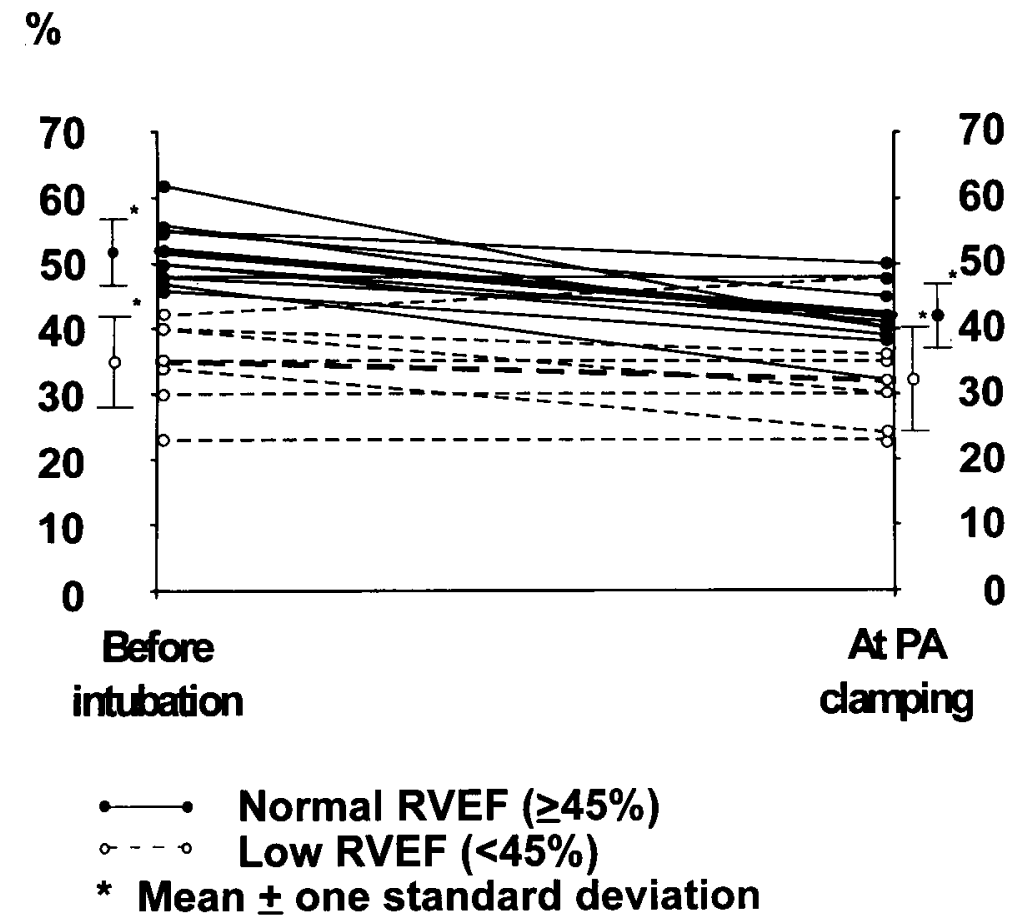

Fig. 2. Changes in RVEF during pneumonectomy. The change in those with normal RVEF at baseline was statistically significant (paired $t$ test, $p=0.0006$ ).

tomy in most. At the time of PA clamping, 30.0\% showed a significant rise in PVR greater than or equal to 200 dyne $\cdot \mathrm{sec} \cdot \mathrm{cm}^{-5}$, although the mean PA pressures in this subgroup remained essentially unchanged.
RVEF values decreased modestly during operation, but only 5 of 20 patients ( $25.0 \%$ ) had RVEF values that fell to levels associated with cor pulmonale (RVEF < $35 \%){ }^{1}$ Although PA pressures and PVR in this 
Table IV. Differences in mean hemodynamic parameters with RVEF $<35 \%$ versus $\geq 35 \%$

\begin{tabular}{|c|c|c|c|c|}
\hline & \multicolumn{2}{|c|}{ Baseline nonintubated $R V E F$} & \multicolumn{2}{|c|}{ PA clamp RVEF } \\
\hline & $\begin{array}{l}<35 \% \\
(\mathrm{n}=3)\end{array}$ & $\begin{array}{l}\geq 35 \% \\
(\mathrm{n}=14)\end{array}$ & $\begin{array}{l}<35 \% \\
(\mathrm{n}=5)\end{array}$ & $\begin{array}{l}\geq 35 \% \\
(\mathrm{n}=15)\end{array}$ \\
\hline RVEF (\%) & $29 \pm 6$ & $48 \pm 7^{*}$ & $28 \pm 4$ & $43 \pm 5^{*}$ \\
\hline $\operatorname{RAP}(\mathrm{mm} \mathrm{Hg})$ & $8 \pm 4$ & $12 \pm 5$ & $15 \pm 4$ & $13 \pm 6$ \\
\hline Systolic PAP (mm Hg) & $41 \pm 12$ & $36 \pm 9$ & $43 \pm 8$ & $38 \pm 9$ \\
\hline Mean PAP $(\mathrm{mm} \mathrm{Hg})$ & $26 \pm 10$ & $26 \pm 6$ & $30 \pm 6$ & $27 \pm 8$ \\
\hline PCWP (mm Hg) & $13 \pm 6$ & $16 \pm 4$ & $19 \pm 5$ & $18 \pm 6$ \\
\hline $\mathrm{Cl}\left(\mathrm{L} / \mathrm{min} / \mathrm{m}^{2}\right)$ & $2.8 \pm 0.7$ & $3.7 \pm 1.2$ & $2.3 \pm 0.7$ & $3.1 \pm 0.6$ \\
\hline $\mathrm{SVI}\left(\mathrm{ml} / \mathrm{m}^{2}\right)$ & $32 \pm 10$ & $44 \pm 10$ & $27 \pm 6$ & $38 \pm 7^{*}$ \\
\hline $\operatorname{RVESVI}\left(\mathrm{ml} / \mathrm{m}^{2}\right)$ & $81 \pm 29$ & $49 \pm 13^{*}$ & $77 \pm 9$ & $50 \pm 12^{*}$ \\
\hline RVEDVI $\left(\mathrm{ml} / \mathrm{m}^{2}\right)$ & $114 \pm 36$ & $94 \pm 18^{*}$ & $106 \pm 10$ & $88 \pm 16$ \\
\hline PVR (dyne $\cdot \mathrm{sec} \cdot \mathrm{cm}^{-5}$ ) & $206 \pm 125$ & $114 \pm 39$ & $231 \pm 109$ & $133 \pm 50$ \\
\hline PVR/RVEF & $6.9 \pm 4$ & $2.4 \pm 0.8^{*}$ & $8.3 \pm 4$ & $3.1 \pm 1^{*}$ \\
\hline $\mathrm{RVP} / \mathrm{V}\left(\mathrm{mm} \mathrm{Hg} / \mathrm{ml} / \mathrm{m}^{2}\right)$ & $0.6 \pm 0.4$ & $0.8 \pm 0.3$ & $0.6 \pm 0.1$ & $0.7 \pm 0.3$ \\
\hline
\end{tabular}

For abbreviations, see Table II.

*Statistically significant difference from value in corresponding column (Student's $t$ test, $p<0.01$ ) at different levels of RVEF.

subgroup did not change significantly from the baseline nonintubated state to PA clamping, four of five patients $(80.0 \%)$ had significant late pulmonary morbidity (class III/IV). No correlation was found between RVEF and PA pressures or PVR at any measuring stage in these 20 patients. RVEF changed directly with stroke work index and inversely with RV end-systolic volume index throughout operation. An inverse relationship between RVEF and RV end-diastolic volume index was seen throughout operation, with the exception of the baseline nonintubated state implying a relationship with RV preload. ${ }^{17}$ Reduction of RVEF during operation paralleled declines in cardiac index and stroke work index, which may reflect increasing afterload. Both RV volumes were elevated throughout operation consistent with levels found in COPD. They did not change appreciably with PA clamping. $R V$ contractility reflected by the peak RV pressure/RV end-systolic volume index ratio remained constant through operation.

Because the origins of postpneumonectomy morbidity and mortality are multifactorial, no single pulmonary function test or hemodynamic measurement can accurately and consistently predict postoperative cardiorespiratory complications. Olsen, ${ }^{18}$ in a recent editorial, succinctly discussed the current state of preoperative assessment of patients requiring lung resection. Although our study does not meet the ideal criteria outlined therein, measurement of RV performance can add another dimension to the decision-making process. RVEF in this series does not correlate with pulmonary function values, PA pressure, or PVR. It, therefore, can be used as an independent parameter in decision-making during pneumonectomy when PA pressure or PVR are elevated. Despite the large cohort of patients with pulmonary hypertension (76.5\%), PVR was normal in $94.1 \%$ before intubation and rose to abnormal levels at PA clamping in only $30.0 \%$. No predictive relationship was found in this small group between the levels of PA pressures or PVR and the occurrence of in-hospital or late postoperative morbidity. RVEF also had no detectable predictive value for in-hospital morbidity. However, at PA clamping, an RVEF less than $35 \%$ consistently identified patients in whom late cardiorespiratory symptoms (NYHA class III/IV) would develop. No late NYHA class III/IV symptoms were seen in patients who had an RVEF greater than or equal 35\%, a PVR less than 200 dyne $\cdot \mathrm{sec} \cdot \mathrm{cm}^{-5}$, and PVR/RVEF less than 5.0 although the majority had pulmonary hypertension. Unfortunately, the detection of half of the cases that would eventually involve significant late cardiopulmonary disability occurred late in the operation at PA clamping. Perhaps a period of exercise during hemodynamic measurements at the baseline nonintubated state might provoke abnormal values of RVEF/PVR in some of these pneumonectomy candidates who have normal values at rest.

We developed a suggested algorithm for the evaluation of the potential pneumonectomy candidate. Those patients with normal pulmonary function testing and no significant cardiopulmonary symptoms can proceed directly to operation. The presence of abnormal pulmonary function and symptoms warrant a split-perfusion lung scan and maximum oxygen consumption determination. A predicted postoperative $\mathrm{FEV}_{1}$ greater than 800 $\mathrm{ml}$ or greater than $40 \%$ and a maximal oxygen consumption $15 \mathrm{ml} / \mathrm{kg}$ per minute should be associated with low mortality and morbidity. If suboptimal values are obtained with these two determinations, a flow-directed 
RVEF catheter can be placed. An RVEF greater than or equal to $35 \%$, a PVR greater than 200 dyne $\cdot \mathrm{sec} \cdot \mathrm{cm}^{-5}$, and a PVR/RVEF ratio less than 5.0 should be associated with low postpneumonectomy morbidity and mortality. Alternative treatment strategies, if available, should be considered when the predicted postoperative $\mathrm{FEV}_{1}$ is less than $800 \mathrm{ml}$ or less than $40 \%$ predicted, maximal oxygen consumption less than $10 \mathrm{ml} / \mathrm{kg}$ per minute, RVEF less than $35 \%$, PVR greater than or equal to 200 dyne $\cdot \mathrm{sec} \cdot \mathrm{cm}^{-5}$, and PVR/RVEF ratio greater than or equal to 5.0. The presence of abnormal pulmonary function, pulmonary hypertension, and elevated PVR alone should not absolutely contraindicate pneumonectomy if other indicators of right heart function remain normal.

We thank Lyn Sheikh for her assistance in the preparation of this manuscript.

\section{R E F ERENCES}

1. Berger HJ, Matthay RA, Loke J, Marshall RC, Gottschalk A, Zaret BL. Assessment of cardiac performance with quantitative radionuclide angiocardiography: right ventricular ejection fraction with reference to findings in chronic obstructive pulmonary disease. Am J Cardiol 1978;41:897905.

2. Biernacki W, Flenley DC, Muir AL, MacNee W. Pulmonary hypertension and right ventricular function in patients with COPD. Chest 1988;94:1169-75.

3. Brent BN, Berger HJ, Matthay RA, Mahler D, Pytlik L, Zaret BL. Physiologic correlates of right ventricular ejection fraction in chronic obstructive pulmonary disease: a combined radionuclide and hemodynamic study. Am $\mathbf{J}$ Cardiol 1982;50:255-62.

4. Mahler DA, Brent BN, Loke J, Zaret BL, Matthay RA. Right ventricular performance and central circulatory hemodynamics during upright exercise in patients with chronic obstructive pulmonary disease. Am Rev Respir Dis 1984;130:722-9.

5. Matthay RA, Niederman MS, Wiedemann HP. Cardiovascular-pulmonary interaction in chronic obstructive pulmonary disease with special reference to the pathogenesis and management of cor pulmonale. Med Clin North Am 1990;74:571-618.
6. Reed CE, Spinale FG, Crawford FA Jr. Effect of pulmonary resection on right ventricular function. Ann Thorac Surg 1992;53:578-82.

7. Lewis JW Jr, Gabriel F, Bastanfar M, Serwin J. Right ventricular performance in patients undergoing pneumonectomy. Chest 1992;102:63S.

8. Kohman LJ, Meyer JA, Ikins PM, Oates RP. Random versus predictable risks of mortality after thoracotomy for lung cancer. J Thorac Cardiovasc Surg 1986;91: $551-4$.

9. Putnam JB, Lammermeir DE, Colon R, McMurtrey MJ, Ali MK, Roth JA. Predicted pulmonary function and survival after pneumonectomy for primary lung cancer. Ann Thorac Surg 1990;49:909-15.

10. Keagy BA, Schorlemmer GR, Murray GF, Starek PJK, Wilcox BR. Correlation of preoperative pulmonary function testing with clinical course in patients after pneumonectomy. Ann Thorac Surg 1983;36:253-7.

11. Bechard D, Wetstein L. Assessment of exercise oxygen consumption as preoperative criterion for lung resection. Ann Thorac Surg 1987;44:344-9.

12. Boysen PG, Block AJ, Olsen GN, Moulder PV, Harris JO, Rawitscher RE. Prospective evaluation for pneumonectomy using the ${ }^{99 \mathrm{M}}$ technetium quantitative perfusion scan. Chest 1977;72:422-5.

13. Fee HJ, Holmes EC, Gewirtz HS, Ramming KP, Alexander JM. Role of pulmonary resistance measurements in preoperative evaluation of candidates for pulmonary resection. J Thorac Cardiovasc Surg 1978;75: 519-24.

14. Grossman W, Braunwald E. Pulmonary hypertension. In: Braunwald E, ed. Heart disease: a textbook of cardiovascular medicine. 4th ed. Philadelphia: W B Saunders, 1992:790.

15. Miller JI. Physiologic evaluation of pulmonary function in the candidate for lung resection. J THORAC CARDIOvaSC SuRG 1993;105:347-52.

16. Boysen PG, Harris JO, Block AJ, Olsen GN. Prospective evaluation for pneumonectomy using perfusion scanning: follow-up beyond one year. Chest 1981;80:163-6.

17. Christianson LC. Ejection fraction: What are its limits? Chest 1980;78:2-3.

18. Olsen GN. Preoperative physiology and lung resection. Scan? Exercise? Both? Chest 1992;101:300-1. 